\title{
BMJ Open Health-related quality of life and its determinants in patients with chronic low back pain at a tertiary hospital in Cameroon: a cross-sectional study
}

\author{
Jeannine Anyingu Aminde (10) , 1,2,3 Leopold Ndemnge Aminde (D) ,,5 \\ Marie Doualla Bija, ${ }^{6,7}$ Fernando Kemta Lekpa, ${ }^{6}$ Felix Mangan Kwedi, ${ }^{6}$ \\ Emmanuel Vubo Yenshu, ${ }^{8}$ Alain Mefire Chichom ${ }^{2}$
}

To cite: Aminde JA, Aminde LN, Bija MD, et al. Healthrelated quality of life and its determinants in patients with chronic low back pain at a tertiary hospital in Cameroon: a cross-sectional study. BMJ Open 2020;10:e035445. doi:10.1136/ bmjopen-2019-035445

- Prepublication history for this paper is available online. To view these files, please visit the journal online (http://dx.doi. org/10.1136/bmjopen-2019035445).

MDB deceased on 17 December 2018

Received 01 November 2019

Revised 24 July 2020

Accepted 29 July 2020

A Check for updates

(c) Author(s) (or their employer(s)) 2020. Re-use permitted under CC BY-NC. No commercial re-use. See rights and permissions. Published by BMJ.

For numbered affiliations see end of article.

\section{Correspondence to} Dr Jeannine Anyingu Aminde; jeannineatemanyingu@ rocketmail.com

\section{ABSTRACT}

Objective To evaluate health-related quality of life (HRQoL) and its determinants in chronic low back pain (CLBP) patients in Cameroon.

Design Observational cross-sectional study.

Setting Tertiary hospital.

Participants There were 150 eligible adults with low back pain of at least 12 weeks who provided informed consent. Of these, 136 with complete questionnaires were analysed.

Outcomes HRQoL was measured using the WHO Quality of Life questionnaire (WHOQOL-BREF). Outcome measures included its four domain (physical health, psychological, social relationships and environmental) scores and two independent scores for overall quality of life (OQOL) and general health satisfaction (GH).

Results Participants had a median age of 52 years, and median pain duration of 33 (IQR: 69) months. The median 0QOL score was 50 (IQR: 25). After multivariable adjustment, tertiary education ( $\beta=11.43,95 \% \mathrm{Cl} 3.12$ to 19.75$)$, age ( $\beta=0.49,95 \% \mathrm{Cl} 0.12$ to 0.87$)$ and being a student ( $\beta=23.07,95 \% \mathrm{Cl} 0.28$ to 45.86 ) contributed to better OQOL. Age ( $\beta=0.57,95 \% \mathrm{Cl} 0.10$ to 1.04 ) and physical-type employment $(\beta=-14.57,95 \% \mathrm{Cl}-25.83$ to -3.31 ) affected $\mathrm{GH}$. Smoking $(\beta=-20.49,95 \% \mathrm{Cl}-35.49$ to -5.48$)$ and radiological anomalies $(\beta=-7.57,95 \% \mathrm{Cl}$ -14.64 to -0.49 ) affected the physical health domain, while disability $(\beta=-0.67,95 \% \mathrm{Cl}-1.14$ to -0.20$)$ and duration of pain $(\beta=-0.13,95 \% \mathrm{Cl}-0.20$ to -0.05$)$ affected the psychological domain. Income $(\beta=14.94$, $95 \% \mathrm{Cl} 4.06$ to 25.81 ) affected the social domain, while education ( $\beta=9.96,95 \% \mathrm{Cl} 1.41$ to 18.50 ) and disability $(\beta=-0.75,95 \% \mathrm{Cl}-1.26$ to -0.24$)$ affected the environmental domain.

Conclusions Our findings suggest that CLBP affects HRQoL and multiple socioeconomic and clinical factors influence its impact on different domains of HRQOL. Multipronged management programmes, especially those that reduce disability, could improve HRQoL in patients with CLBP.

\section{INTRODUCTION}

Low back pain (LBP) is an expanding health problem with a major impact on the general
Strengths and limitations of this study

- To the best of our knowledge, this is the first study in Cameroon to investigate health-related quality of life (HRQoL), in chronic low back pain patients and to explore the determinants of specific HRQoL domains.

- We used a widely validated tool (WHOQOL-BREF) that allows for applicability across cultures and for comparisons between various settings.

- The absence of population norms for WHOQOL-BREF in Cameroon to serve as a reference limited our ability to establish relevant comparisons.

- We acknowledge that the cross-sectional design used in this study limits the establishment of causality in the associations identified.

health and performance of populations worldwide. More than one-third (38\%) of the world's population suffer LBP in the course of a year. ${ }^{12}$ In 2017, LBP accounted for 850 years lived with disability (YLD) per 100000 population, and was the leading cause of disability globally. ${ }^{3}$ On average, one-in-three adults in Africa have LBP. This was confirmed in a systematic review that reported a pooled adult prevalence of $32 \%$ and an average lifetime prevalence of $62 \%$. $^{4}$

Cameroon is a lower-middle-income country in sub-Saharan Africa with a population of above 25 million $^{5}$ organised into 10 regions. The health system of the country consists of a public and private sector. The public sector which is the main health service provider is organised in a pyramidal manner under the control of the Ministry of Health and at its base, 189 health districts. Health districts are primary care units made of several integrated health centres and a district hospital. Healthcare provision in these centres is largely ensured by nurses supported by doctors in 
a central district hospital. Specialist health services are generally localised within second-level facilities (regional hospitals) in each of the 10 administrative regions of the country. Tertiary hospitals are mainly located in the administrative (Yaounde) and economic (Douala) capital cities, and provide the highest level of specialised care. While little is known about the burden of LBP in primary care in Cameroon; it is the leading cause of specialist rheumatological consultations. ${ }^{67}$ It equally causes considerable disability ${ }^{8}$ and was considered the leading cause of YLD in Cameroon in 2017, with 652 YLD per 100000 populations, increasing by $2 \%$ since $2015 .^{3}$

Pain, muscle tension or stiffness, localised below the costal margin and above the inferior gluteal folds, with or without leg pain (sciatica) ${ }^{9}$ is referred to as acute LBP when it lasts less than 6 weeks, sub-acute LBP when it lasts 6-12 weeks, and chronic LBP (CLBP) when it lasts longer than 12 weeks. ${ }^{10}$ Clinical and research emphasis is generally on CLBP because chronic pain is a recognised cause of reduced quality of life (QoL). ${ }^{11}$

QoL, a subjective concept, is defined in simple terms as a person's evaluation of his or her well-being and functioning in diverse domains of life. ${ }^{12} \mathrm{WHO}$, defines QoL as an individual's perception of his or her position in life, in the context of the culture and value systems in which he or she lives, and in relation to his or her goals, expectations, standards and concerns. ${ }^{13}$ Health-related QoL (HRQoL) though often used interchangeably with $\mathrm{QoL}^{14}$ is considered by some as distinct or as a subconcept of QoL. ${ }^{1516}$ HRQoL pertains to an individual's evaluation of their experiences, and expectations in health-related aspects of their lives, notably; physical function, psychological well-being, subjective symptoms, social function and cognitive function. ${ }^{14}{ }^{15}$ It is thought to equally extend to the individual's perception of health correlates like health risks, social support, sociocultural beliefs and economic status. ${ }^{17}$

The HRQoL of patients with CLBP (largely in nonAfrican settings) has been explored and found to be reduced or suboptimal. ${ }^{18-20}$ Besides the obvious pain, multiple factors are implicated in this reduced HRQoL, some of which include; disability, fear of movement, impaired sleep quality, depression, anxiety, low income, low educational levels, lumbosacral radiculopathy and overweight/obesity. ${ }^{21-26}$ Among these, disability (impaired physical function) is considered a core issue. Disability results in considerable work absence, lower productivity and poorer HRQoL. ${ }^{27-29}$

The effect of CLBP on HRQoL has hitherto, not been investigated among Cameroonian patients. Evidence of the possible contribution of unique demographic, clinical and socioeconomic factors in low-resource subSaharan African settings, and their influence on HRQoL in patients with CLBP is limited. To bridge this gap, we sought to assess HRQoL in Cameroonian CLBP patients using the WHO Quality of Life brief (WHOQOL-BREF) tool. We investigated the prevalence of perceived poor QoL, the prevalence of health dissatisfaction and the factors associated with various domains of HRQoL in these patients.

\section{MATERIALS AND METHODS}

\section{Study design and setting}

A cross-sectional study was conducted from January to March 2017 at the Douala General Hospital (DGH). The DGH is a tertiary hospital that receives patients from all ten regions of Cameroon. The study was carried out at the rheumatology unit that has three consultant rheumatologists, who (on alternate days) run the outpatient consultations of the unit. Douala is a major city in the Littoral region and is the economic capital of Cameroon, with an estimated population of 2.7 million. ${ }^{30}$

\section{Patient and public involvement statement}

This research did not involve patients or public in the initial study design. However, patient representatives were invited to test the acceptability of two popular HRQoL measuring tools to determine which to use as principal outcome measure in our population (considering ease of understanding and time burden). Patients were again recruited to pretest the final questionnaire. Patients were not involved in the writing or editing of this document and were also not involved in the dissemination plans.

\section{Sampling technique and study participants}

The Cochran formula $\left(\mathrm{n}=\mathrm{Z}_{1-\alpha / 2}{ }^{2} \mathrm{SD}^{2} / \mathrm{d}^{2}\right)$ for calculating sample size required to estimate a variable mean was used. We set the confidence level to $95 \%$, and adopted a 5 -point difference in the overall QoL (OQOL) score (2) of WHOQOL-BREF as our absolute error or precision and a SD of 24.2 in the OQOL, derived from a similar study in LBP patients in Brazil in 2013. ${ }^{27}$ We obtained an estimated minimum sample size of 90 CLBP patients.

Consecutive sampling was used to recruit eligible and consenting adult patients aged $18-70$ years. All patients presenting either de novo or for follow-up visits with pain, muscle tension or stiffness, localised below the costal margin and above the inferior gluteal folds lasting no less than 12 weeks were considered. For clarity, the affected area of the body was shown in a human diagram. We excluded any patients who were pregnant, suspected to have cauda equina syndrome or recent trauma. In addition, patients were excluded if they were unable to comprehend questions despite interviewer assistance. Figure 1 shows the flow diagram of participant selection leading to the final study sample.

\section{Study procedures and data collection}

Patients who fulfilled the study eligibility criteria and provided written informed consent were interviewed using a pretested structured questionnaire. Data collected were sociodemographic information, clinical data, as well as disability and QoL assessment of participants. Questionnaires were available in English and French, the two official languages in Cameroon. 


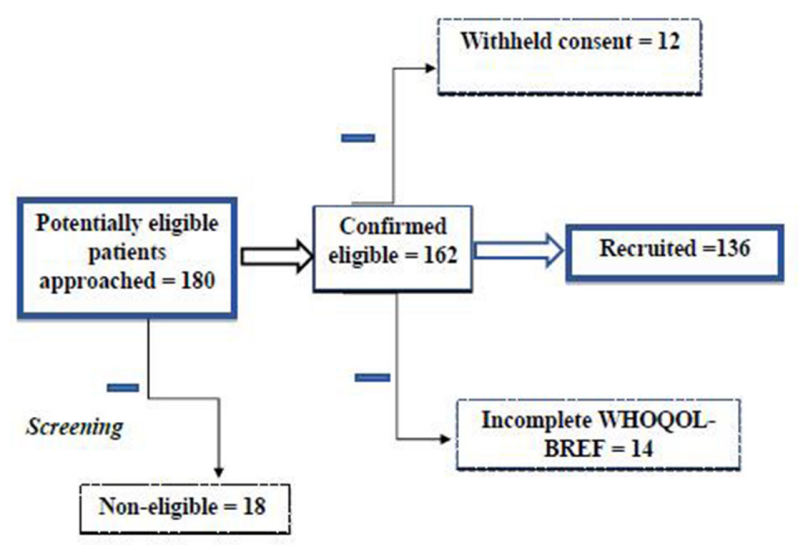

Figure 1 Derivation of final study population. WHOQOLBREF, WHO Quality of Life brief.

\section{Sociodemographic characteristics}

Data on the following variables were collected: gender, age, marital status (single, married or widowed), employment status (employed, housewife, student, unemployed/ retired), employment type (physical, non-physical), level of education (no education, primary, secondary and tertiary education) and average monthly income (<FCFA50 000, FCFA50 000-FCFA100 000, FCFA100 000FCFA300 000, $>$ FCFA300 000 FCFA (US $\$ 1=$ FCFA530)). Information on other characteristics like smoking status (current smoker, former smoker and non-smoker), alcohol use and units of alcohol consumed per week (for consumers) was also obtained.

\section{Clinical characteristics}

To clearly elucidate the duration of LBP, and cognizant of the remitting/recurring nature of LBP, the duration of pain was assessed in two ways. The total duration of LBP was recorded by asking participants the question; 'For how many years (months) have you had an ongoing low back pain problem?'. This was adapted from the recommendations of the CLBP Research Task Force of the American National Institute of Health Pain Consortium. ${ }^{31}$ Duration of their current pain episode was assessed by asking the question; 'How long (years/months) has it been since you went for a whole month without low back pain?', based on the definition of an LBP episode proposed by de Vet $e t a l{ }^{32}$

The assessment of pain intensity was done using the $100 \mathrm{~mm}$ Visual Analogue Scale. Patients were asked to rate their pain level at the time of the interview. Other clinical data recorded included: leg pain, lower limb numbness/paresthesia (tingling, burning, electric-currents, numbness or 'pins and needles' in the lower limbs), and bladder/bowel dysfunction symptoms (uncontrollable urges to urinate/stool, urine/stool leakages or undue strain in stooling/initiating urine). In this study, we did not specifically identify the aetiology of these symptoms. In addition, the presence or absence of any comorbidity was documented. Patients' weight and height were measured and used to compute their body mass index. Seca scales were used for weight measurement during which participants had to be without footwear and have on light clothing. For height measurement, the adult Leicester stadiometer was placed against a wall, and participants (without shoes) stood upright while their heels and occiput were on the stadiometer. Measures were to the nearest $0.5 \mathrm{~cm}$ for height, and one decimal place for weight.

\section{Assessment of disability}

The Roland Morris Disability Questionnaire (RMDQ), a subjective 24-item back pain-specific tool that assesses impairment in activities of daily living was used to assess disability. Responses to the 24 items were by either 'yes' or 'no', and a total score ranging from 0 to 24 was generated by counting the number of 'yes' responses (yes=1 point and no=no point). Higher scores imply greater disability. The RMDQ is easily understood and available in validated English and French versions. ${ }^{33}$ Work absence due to LBP was assessed in terms of disability days, which was defined as the number of days of restricted routine activity or work absence because of CLBP occurring within the 30 days preceding the interview.

\section{Assessment of HRQoL (WHOOQOL brief version: WHOQOL-BREF)}

Most tools for measuring HRQoL are self-report questionnaires. The WHOQOL-BREF tool is a generic self-report HRQoL questionnaire (applicable to 'healthy' and 'sick' persons). It was developed using data from 15 countries including sub-Saharan African countries like Zambia and Zimbabwe. It is the brief version of the original one hundred item tool; WHOQOL-100. It is designed to be cross-culturally applicable and has been applied in clinical practice and research to measure health outcomes, monitor disease progress and compare health states even across countries. In studies comparing generic HRQoL tools, WHOQOL-BREF was found to have good-toexcellent psychometric properties across disease states (especially in chronic disease) when compared with the most widely used of them all, the Short Form 36 Health Survey questionnaire (SF-36). ${ }^{16} 34$

The WHOQOL-BREF tool consists of 26 items (questions/facets), 24 of which are divided into four domains: physical health domain (PHD), psychological domain (PSD), environmental domain (END) and social relationships domain (SRD). There are two separate items evaluating the individual's satisfaction with their state of health (general health score) and individual's perception of QoL (OQOL score). Scores are organised such that higher scores imply better HRQoL. PHD explores activities of daily living, including dependence on medicines/medical aids, energy and fatigue, mobility, pain and discomfort, sleep and rest, and work capacity. PSD explores bodily image and appearance, negative feelings, positive feelings, self-esteem, spirituality/religion/personal beliefs and thinking, learning, memory and concentration. SRD explores personal relationships, social support and sexual activity. END explores financial resources, freedom, physical safety and security, accessibility and quality of health 
and social care, home environment, opportunities for acquiring new information and skills, participation in leisure activities, physical environment, pollution, noise, traffic and climate, and transport.

The WHOQOL-BREF questionnaire can be selfadministered or interviewer administered and responses are still valid allowing a period of $2-4$ weeks. ${ }^{35}$ It was chosen due to its cross-cultural applicability, low administrative burden, sensitivity and responsiveness in chronic diseases states, and the availability of validated versions in Cameroon's national official languages (English and French). Each item of WHOQOL-BREF is scored on a 5-point likert scale. The item scores are then transformed into domain scores following the steps described in the WHOQOL-BREF manual. ${ }^{35}$ While there are no established cut-off points for the WHOQOL-BREF domains to distinguish between 'good' and 'poor' HRQoL, two studies transformed the two individual items (general health score and OQOL score) into binary outcomes. In these studies, respondents with two points or less on a total of five (ie, rated their QoL or health satisfaction as 'poor' or 'very poor'), were considered to have a poor outcome. 2036

Written consent was obtained from all participants after careful explanation of the study scope and objectives. Strict anonymity and confidentiality were maintained during the handling of patient's records and response data. The study adhered to the World Medical Association's Declaration of Helsinki, ${ }^{37}$ and the study is reported in accordance with the Strengthening the Reporting of Observational Studies in Epidemiology guidelines.

\section{Data management and statistical analysis}

Data were cleaned and analysed using the SPSS v.20. Continuous variables were tested for normality using the Shapiro-Wilk's test. For ease of comparison, we report both the means with SD, and the medians with 25th and 75 th percentiles for all variables. Categorical variables were summarised using counts and percentages. The prevalence of poor OQOL and poor general health satisfaction (GHS) in CLBP was also estimated. Poor OQOL was considered as rating QoL 'poor' or 'very poor' that is, cut-off scores of less than 3 points out of 5 of the original item score while moderate-to-good OQoL ( $\geq 3 / 5$ points) for rating QoL 'neither poor nor good', 'good' or 'very good'. Poor GHS $(<3 / 5$ points), for rating satisfaction with health as 'poor' or 'very poor' and moderate-togood GHS ( $\geq 3 / 5$ points), patients rating satisfaction with health as 'neither poor nor good', 'good' or 'very good'.

GHS and OQOL scores were subsequently analysed as continuous outcome variables. In bivariate analysis, Spearman's correlation coefficient was used to investigate associations of continuous independent variables with WHOQOL-BREF scores (PHD, PSD, END, SRD, GHS and OQOL scores). In cases where WHOQOL-BREF scores were normally distributed we used analysis of variance to explore differences in WHOQOL-BREF scores across categories, while for non-normally distributed data, we

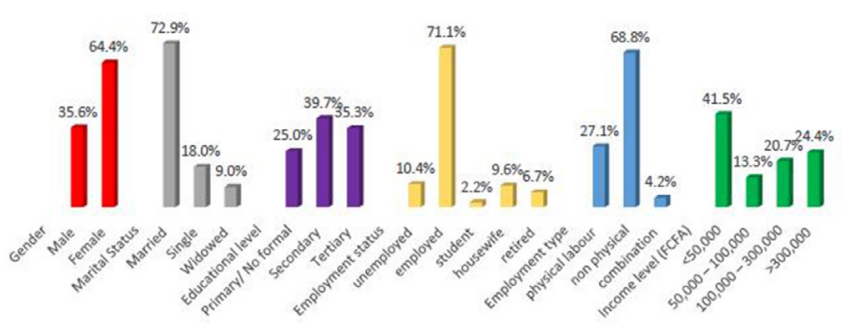

Figure 2 Description of sociodemographic characteristics of the study participants $(n=136)$.

used the non-parametric Kruskal-Wallis test. Variables with a $\mathrm{p}<0.1$ in bivariate analysis were included in multivariable models. Because residuals were approximately normally distributed, we used multivariate linear regression models to determine factors independently associated with WHOQOL-BREF scores while adjusting for age, sex and other confounders. We checked for evidence of multicollinearity in the independent continuous variables via a correlation matrix and then ran collinearity diagnostics to assess their tolerance and variance inflation factor (VIF). All VIFs were less than two, suggesting absence of any multicollinearity. Statistical significance was set at $\mathrm{p}<0.05$.

\section{RESULTS}

One hundred and eighty potentially eligible patients CLBP patients (identified based on examination of patient's hospital records) were approached. They were screened via questioning to exclude pregnancy and trauma, and to confirm ability to understand questions. One hundred and fifty, who were confirmed eligible and provided consent, were included in study. However, only one hundred and thirty-six with complete WHOQOLBREF questionnaires were used in the final analysis (figure 1). The median (25-75th percentile) age of participants was $52(43-60)$ years, with a female: male

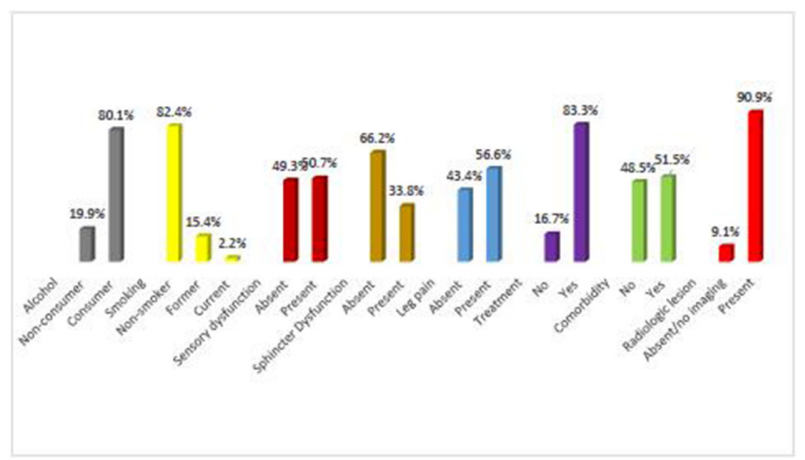

Figure 3 Description of the clinical characteristics of the study participants $(n=136)$. 
Table 1 Measures of central tendency, spread and correlations of variables with WHOQOL-BREF scores

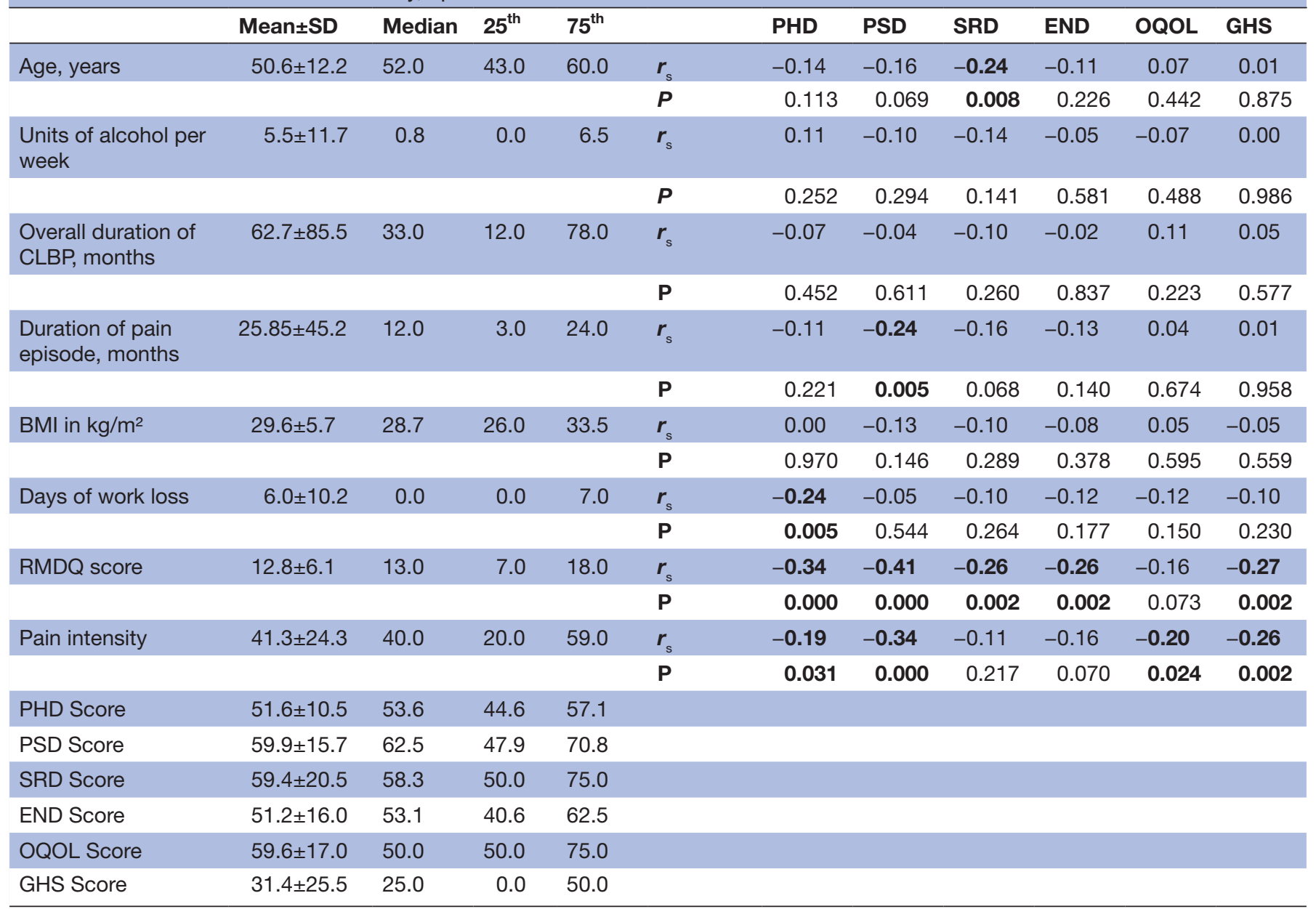

${ }^{\star}$ Bold values refer to statistically significant associations

BMI, bodymass index; CLBP, chronic low back pain; END, environmental domain; GHS, general health satisfaction; OQOL, overall quality of life; PHD, physical health domain; PSD, psychological domain; RMDQ, Roland Morris Disability Questionnaire; rs, Spearman's correlation coefficient; SRD, social relationship domain; WHOQOL-BREF, WHO Quality of Life brief.

ratio of 1.8:1. Detailed characteristics of our study participants can be found in figures 2 and 3 .

\section{Pain and duration of CLBP}

Overall, the median (25-75th percentile) duration of CLBP was 33 (12-78) months. The median duration of the ongoing pain episode was 12 (3-24) months and the median perceived pain intensity score at the time of the interview was $40(20-59) \mathrm{mm}$. Participants on average reported $6 \pm 10$ days of work loss in the previous month due to LBP (table 1).

Health-related quality of life

With the exception of the END score, all WHOQOL-BREF domain scores were not normally distributed. The median OQOL score of CLBP patients at DGH was 50.0 (50.0-75.0). The median GHS score was 25 (0-50), and significantly lower than the OQOL score $(\mathrm{p}<0.001)$. Among the four domain scores, the highest score was in the PSD, median: 62.5 (47.970.8). The lowest was the END median: 53.1 (40.6-62.5), see table 1 for more details. Overall, 7.4\% had a poor perceived OQOL, while $64.7 \%$ had poor GHS.
Factors influencing HRQoL domains

PHD: In univariate analysis (tables 1 and 2), the factors significantly associated with poor PHD included; longer days of work absence, higher disability scores, higher reported pain intensity, current smoking, documented radiological disease, and primary or no formal education versus tertiary-level education.

In multivariate analysis, factors that independently influenced HRQoL in the physical domain included; current smoking $(\beta=-20.49, \quad p=0.008)$ and documented radiological disease $(\beta=-7.57, p=0.036)$. The model explained $22.6 \%$ of the variance in the PHD scores (table 3 ).

PSD: In the univariate analysis, factors associated with poorer HRQoL in the PSD were; the duration of a pain episode, higher RMDQ score and secondary education when compared with tertiary education (reference category) (tables 1 and 2).

However only the RMDQ score $(\beta=-0.67, \mathrm{p}=0.006)$ and the LBP episode $(\beta=-0.13, \mathrm{p}=0.001)$ significantly influenced the 


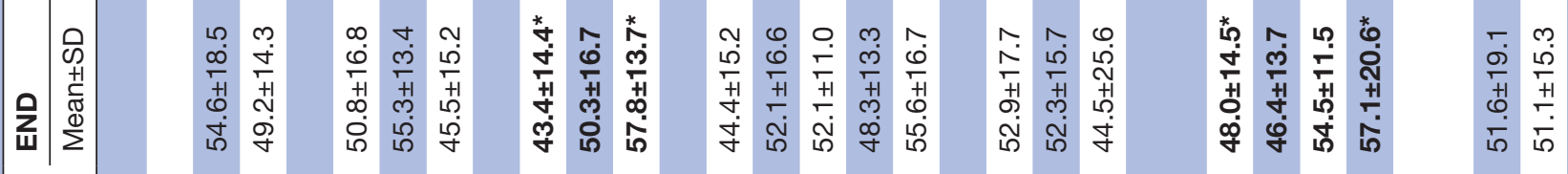

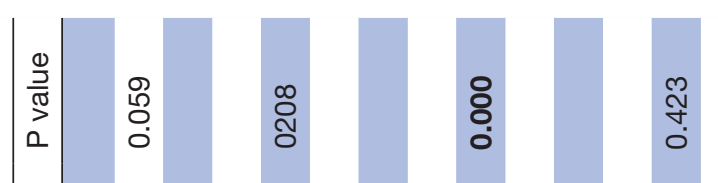

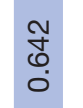

สับ

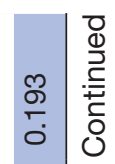

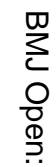

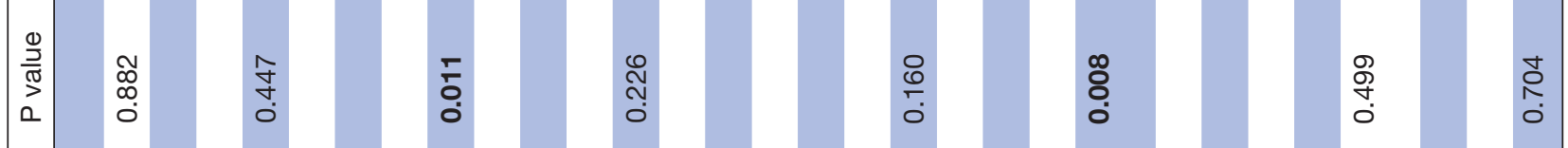

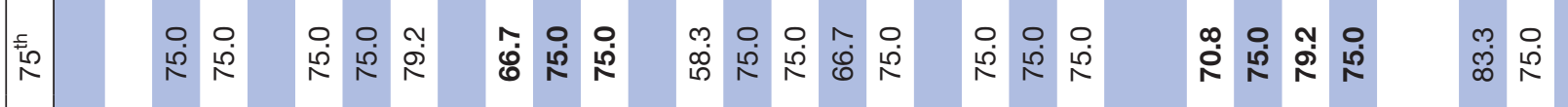

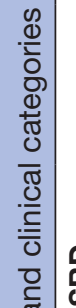

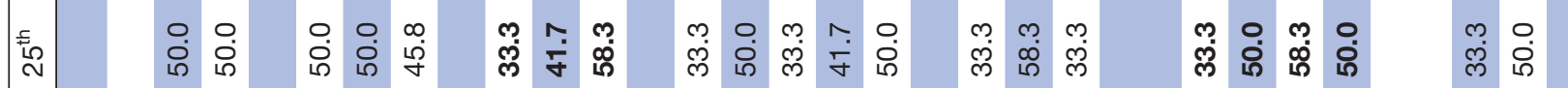

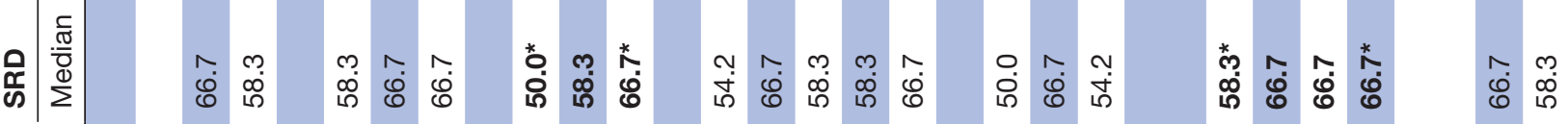

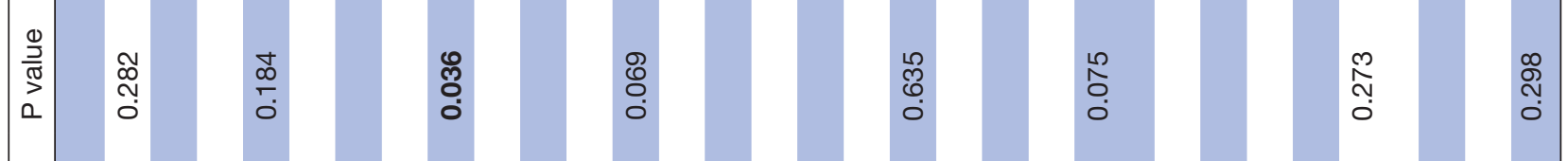

ل

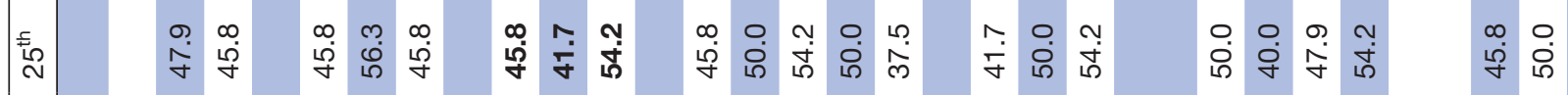

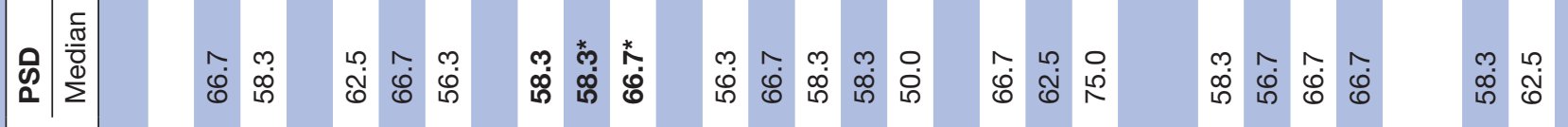

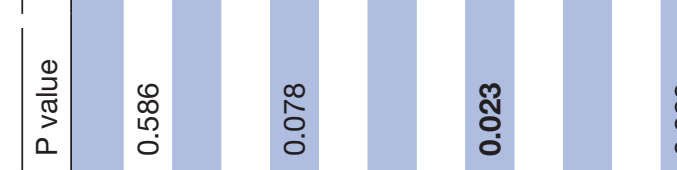

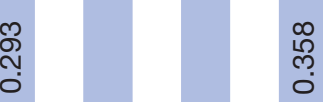

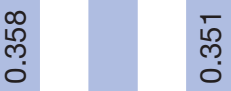

@o

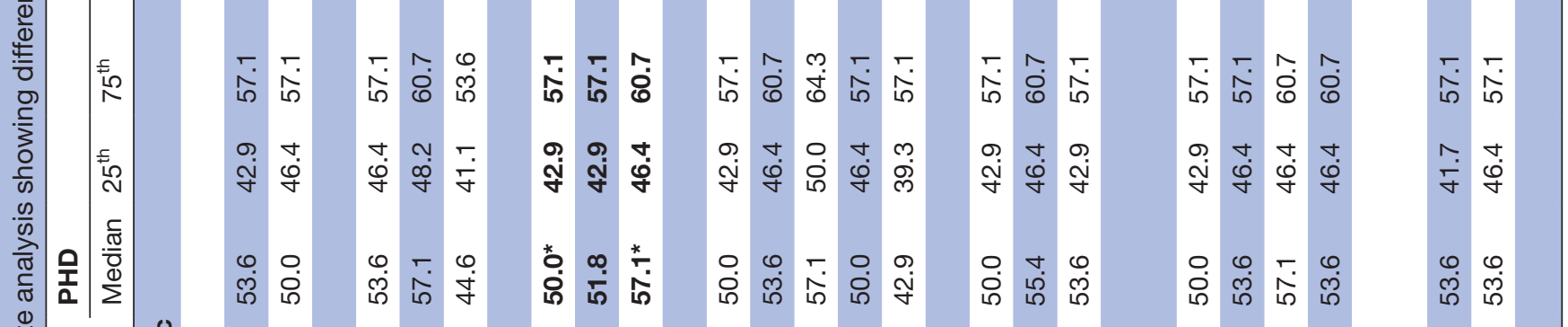




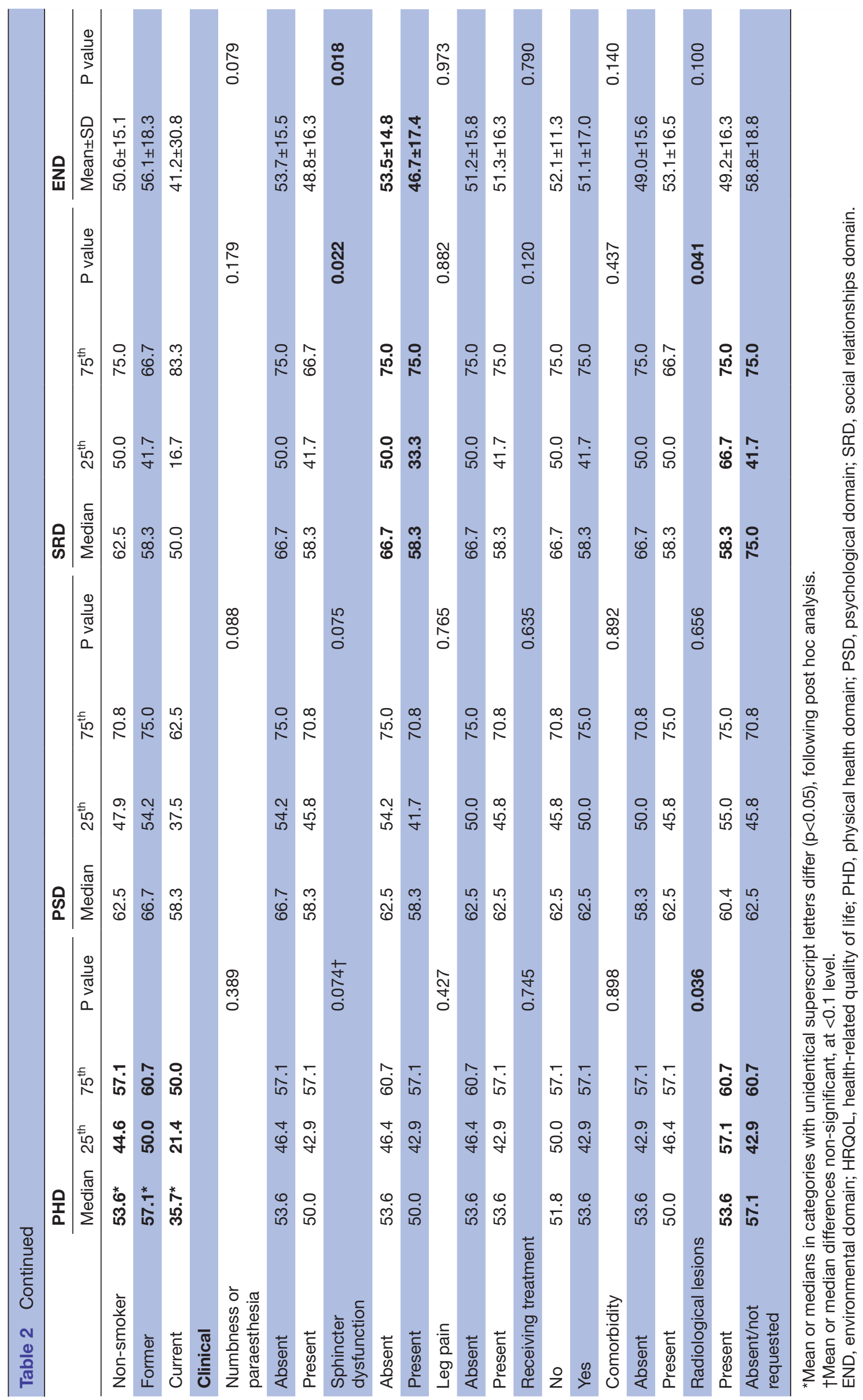


-

- -

1

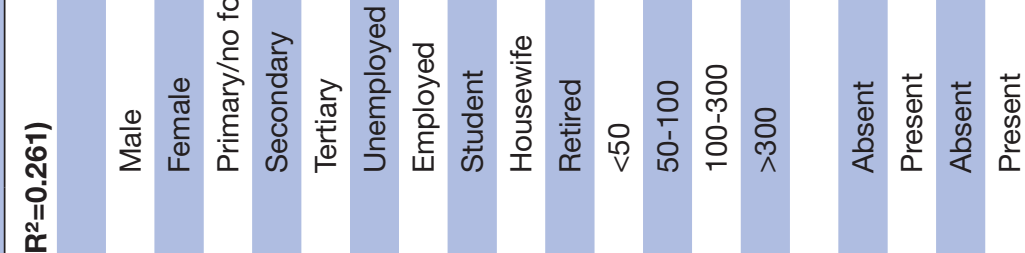

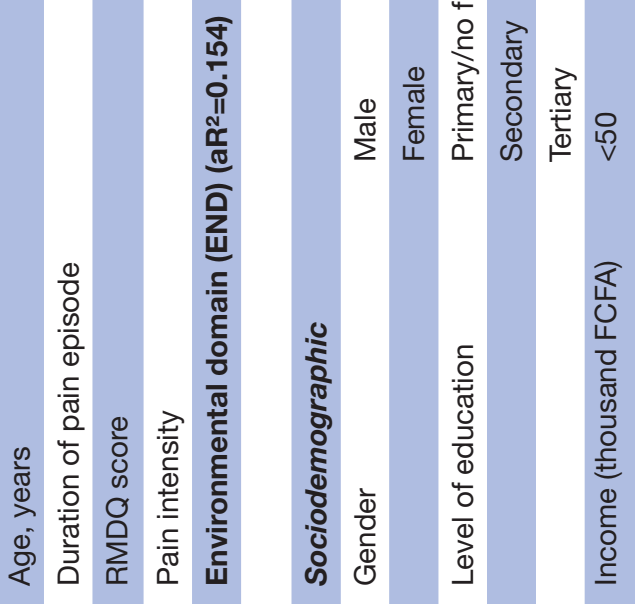

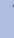

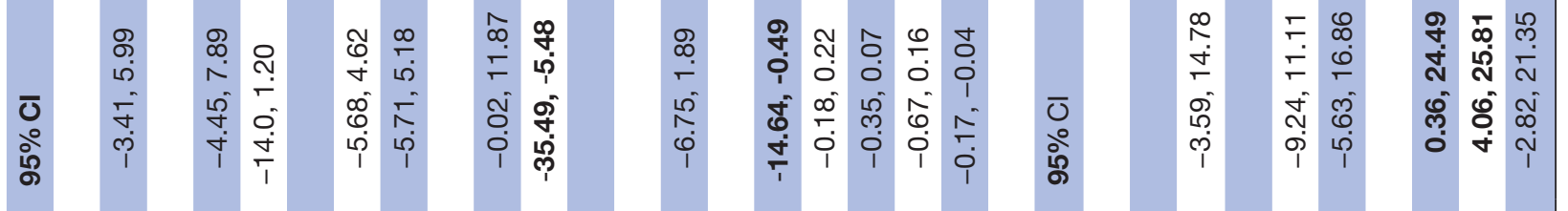

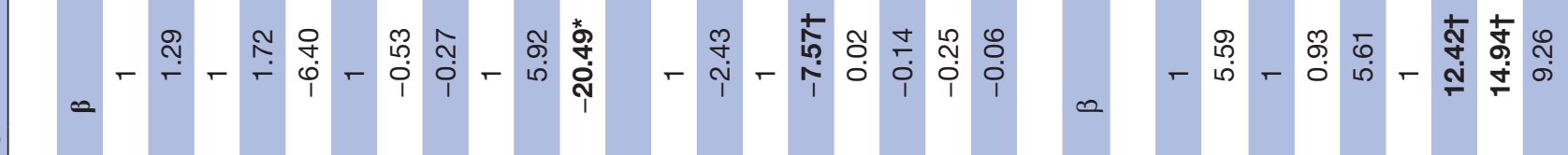
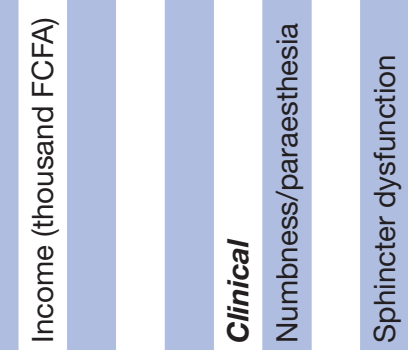

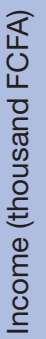

专 क⿱ 口)

르

巳ั̊

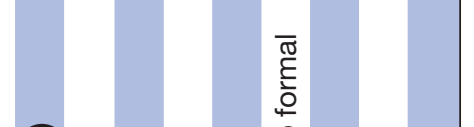

这

$\frac{\infty}{0}$

产

क

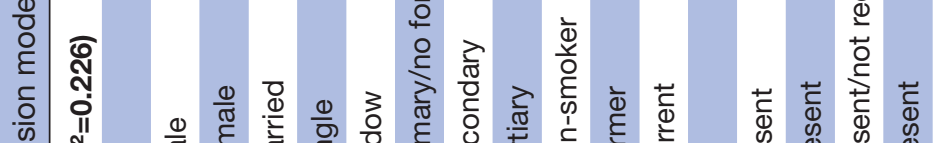

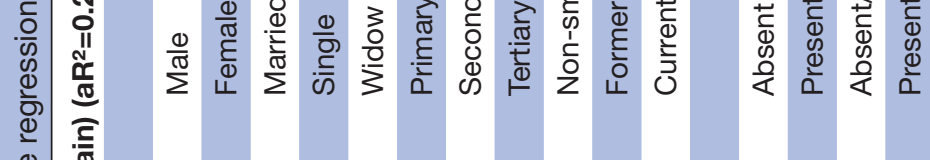

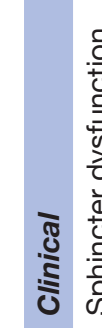

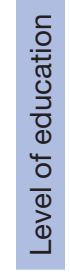

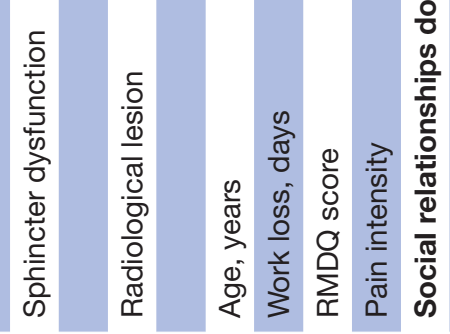

है

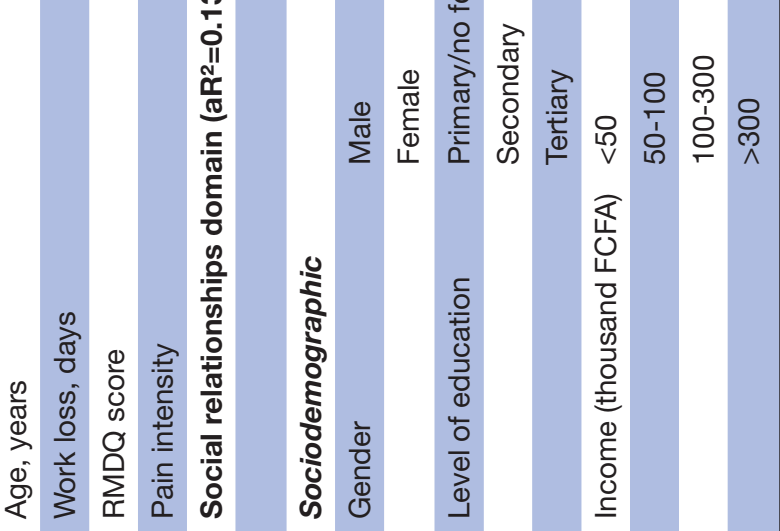

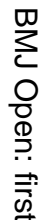

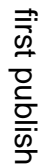

(2)

$\overrightarrow{0}$

$\overrightarrow{\vec{\omega}}$

흥.

옹

फ్

जि

웅

8

윰

N

ํำ

产

읔

궁

홍

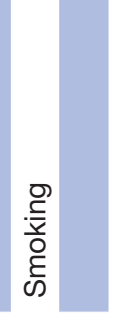

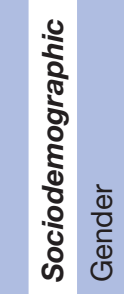




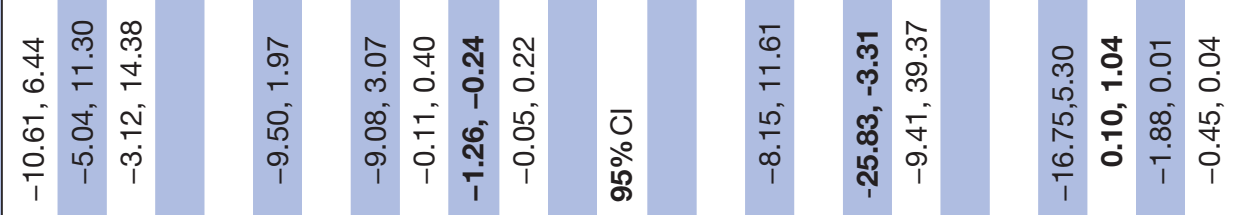

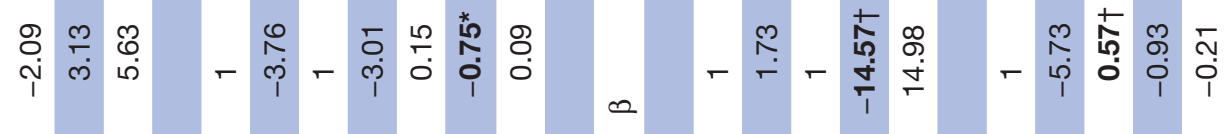

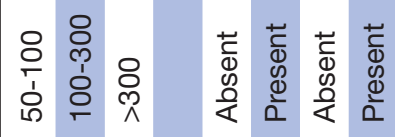

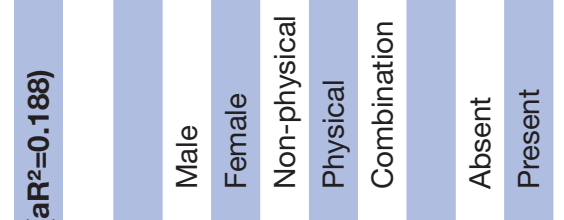

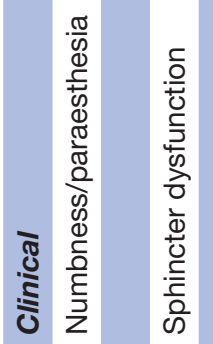

등

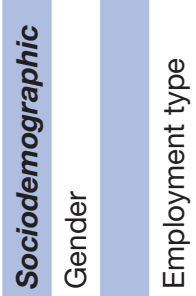

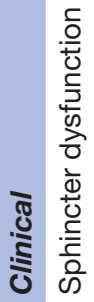

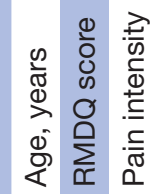

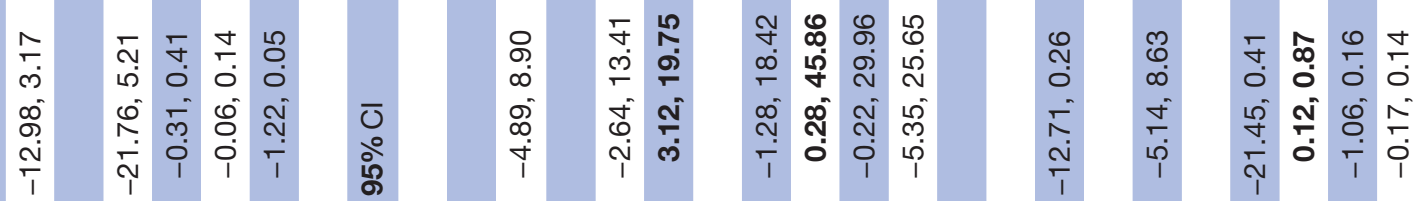

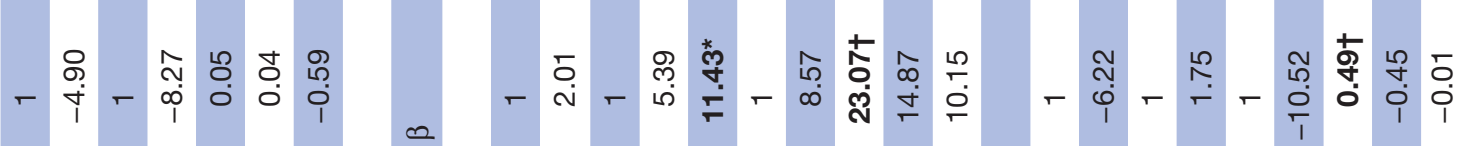

ลิ 
PSD in multivariate analysis. The model explained $26.1 \%$ of the variance in the PSD scores (table 3).

SRD: Lower SRD scores were associated with older age, sphincter dysfunction, documented radiological lesions, primary education versus tertiary and an income below FCFA50 000 versus one above FCFA300 000 (tables 1 and 2).

In the multivariate model, the only independent predictor of SRD was income. Monthly incomes of FCFA50 000-FCFA100 $000(\beta=12.42, p=0.044)$ and FCFA100 000FCFA300 $000(\beta=14.94, p=0.008)$ were associated with better SRD scores when compared with income below FCFA50 000. The model explained $13.4 \%$ of the variance in SRD scores (table 3).

END: Univariate analysis revealed that lower END scores were associated with higher RMDQ scores, primary vs tertiary education, an income below FCFA50 000 vs one above FCFA300 000, and sphincter dysfunction (tables 1 and 2).

Factors independently associated with higher END scores were; tertiary-level education $(\beta=9.96, p=0.023)$ and RMDQ score $(\beta=-0.75, p=0.004)$. The model explained $15.4 \%$ of the variance in END scores (table 3 ).

OQOL and GHS: Higher perceived pain intensity was significantly associated with lower GHS and OQOL scores. Disability negatively influenced GHS but not OQOL. OQOL differed significantly in those with limb numbness/paraesthesia while the GHS score was significantly lower in those employed in physical effort requiring jobs compared with those who were not (tables 1 and 4 ).

In the multivariate analysis, tertiary education $(\beta=11.43$, $\mathrm{p}=0.008)$, increasing age $(\beta=0.49, \mathrm{p}=0.010)$ and being a student $(\beta=23.07, \mathrm{p}=0.047)$ were independently associated with OQOL. The model explained $12.9 \%$ of the variance in the OQOL score (table 3). Among the domain scores, higher SRD scores $(\beta=0.26, p=0.001)$ and END scores $(\beta=0.43, p<0.001)$ were associated with better OQOL. The model explained $35 \%$ of the variance in the OQOL score after adjusting for age, gender, educational level and employment status (table 5).

Based on multivariate analysis, variables independently associated with GHS were; age $(\beta=0.57, p=0.017)$ and physical-type employment $(\beta=-14.57, \mathrm{p}=0.012)$, with the model explaining $18.8 \%$ of the variance in GHS scores (table 3). No domain score was significantly related to the GHS score in adjusted multivariate analysis (table 5).

\section{DISCUSSION}

Chronic pain is a recognised cause of reduced QoL, but the dimensions and extent of the impact it has on HRQoL are subject to variations based on the individual, the disease and even the environment. Accordingly, the aim of this study was to describe HRQoL and its determinants in CLBP patients in Cameroon. We found that determinants of HRQoL differed for various WHOQOLBREF component domains. Being a current smoker and having radiological disease predicted poorer physical health, while increased disability (higher RMDQ scores) and longer LBP episodes predicted poorer psychological health. Higher income predicted better social relationships while higher levels of education and less disability (lower RMDQ scores) predicted better environmental health. Tertiary education, older age and being a student predicted better OQOL. On the other hand, older age and non-physical-type employment were associated with greater GHS.

The average OQOL score for CLBP patients in our study was about half of the maximum score. Similar scores were reported among other CLBP patients in countries with better living standards (higher per capita gross domestic product) such as Brazil and Poland. ${ }^{2738-40}$ While, in studies with a mixed population of acute and CLBP patients, higher average scores were reported, ${ }^{18} 19$ strengthening the argument that CLBP has an impact on QoL, and the chronic nature of the pain likely contributes to this effect. ${ }^{11}$

The average GHS score for our CLBP patients was significantly lower than the average OQOL score, as was similarly reported in Polish patients. ${ }^{41}$ More so, dissatisfaction with general health was common (more than two-thirds of our patients), while less than a tenth rated their QoL as poor. In an Austrian study, ${ }^{20}$ though a similar disparity was observed between the two scores, health dissatisfaction was less common (about a quarter of their patients) than in our cohort. In addition, the proportion of persons in this study who rated their OQOL as 'very bad' or 'bad' was comparable to ours $(8.6 \%$ in men and $14.7 \%$ in women). This may be linked to the fact that patients in this study were recruited from the community (as opposed to hospital setting in our study) and possibly in better physical health states, hence more satisfied with their health comparatively. It could also be a reflection of better access to quality healthcare for the Austrian population in general. On the other hand, the consistent disparity between health satisfaction and self-rated OQOL potentially indicates that while CLBP clearly influences perceived health status, its effect on QoL is seemingly not a direct one. QoL appears to be a broader indicator with multiple determinants.

Moving into the specific domain scores, the END score was the most impaired HRQoL domain in our patients. A similar finding was observed in Brazil. ${ }^{38}$ However, the physical domain which was scored slightly better than the END by our patients (third most impaired domain) has been frequently identified as the most affected in similar patient groups in Iran, Austria, Brazil, Poland and Bosnia. ${ }^{18} 20273942$ When consideration is given to the specific items (satisfaction with finances, physical security, accessibility of healthcare, quality of health/social care, home environment, participation in leisure activities, pollution, noise, traffic and transport) assessed in the END score, it is likely that the low scores found in our patients may reflect the comparatively low standards of living in our population, and limited infrastructure adapted for persons with disability. 


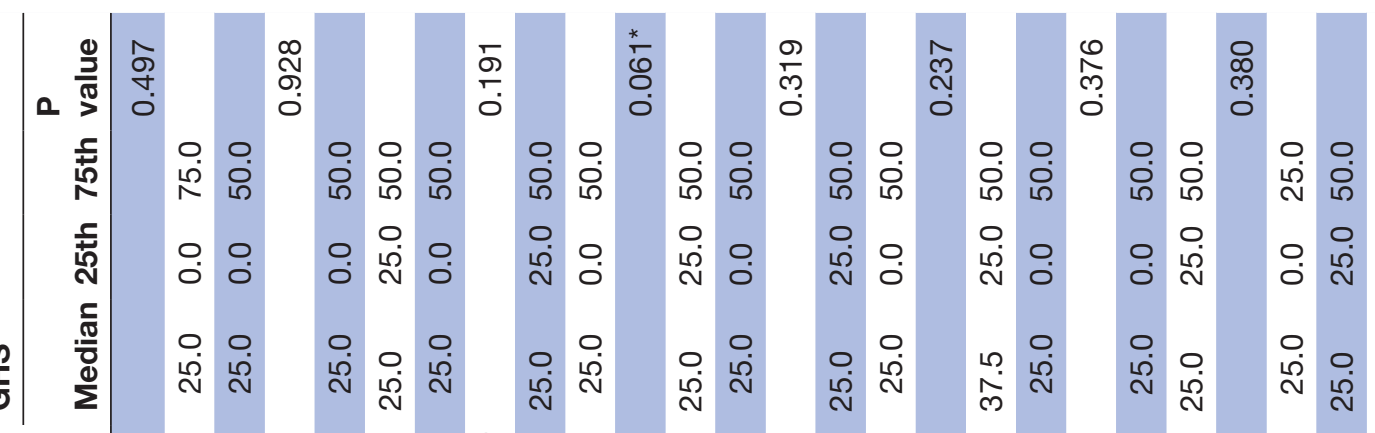

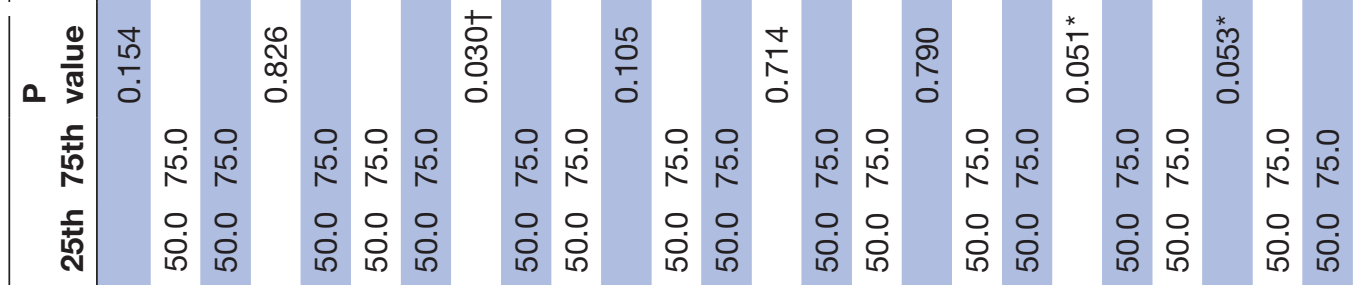

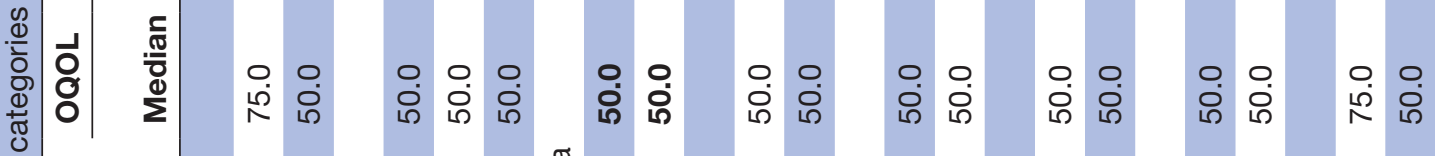

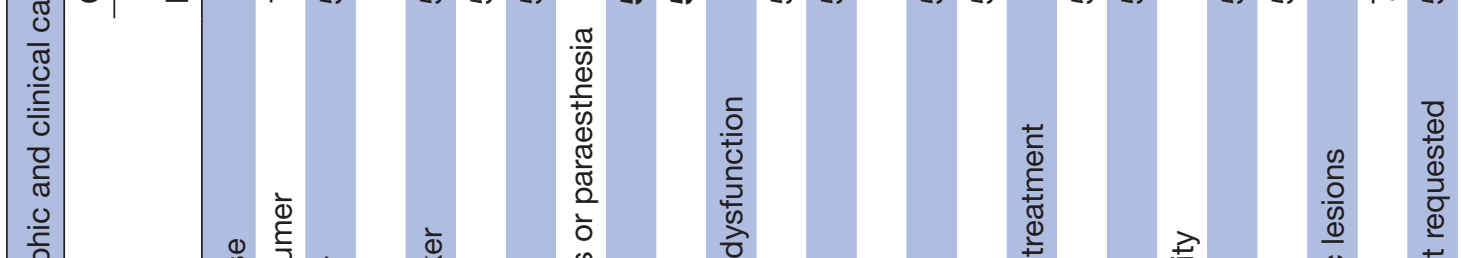

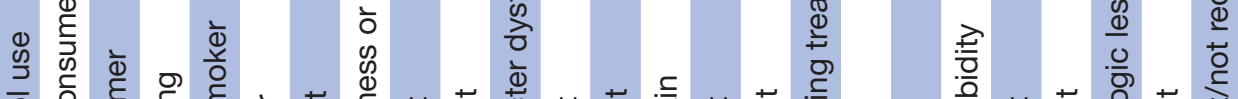

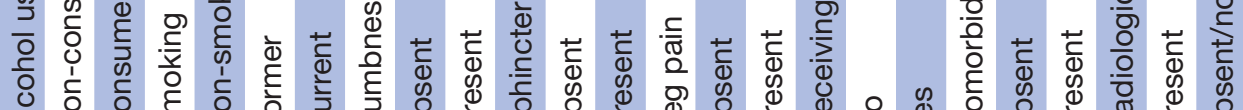

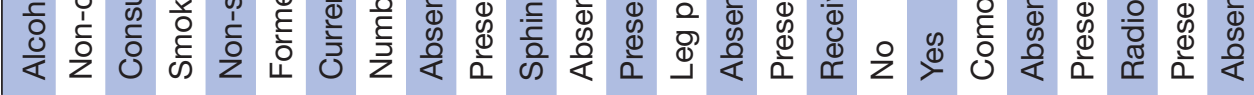
a $\frac{\sqrt{2}}{\frac{10}{2}}$ 每 嗀

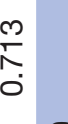

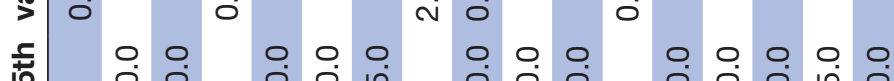

ถ

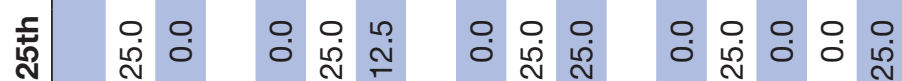

○. 0

\begin{tabular}{lll}
0 \\
0 \\
0 \\
$\frac{0}{0}$ \\
$\frac{0}{0}$ \\
\hline
\end{tabular}

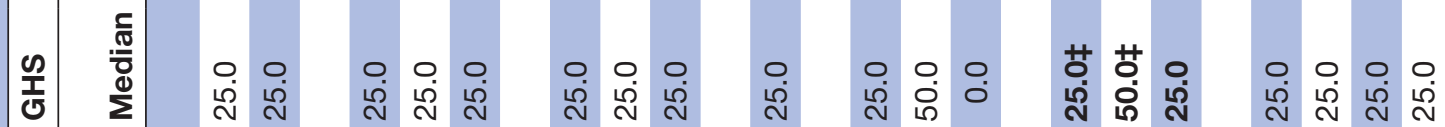

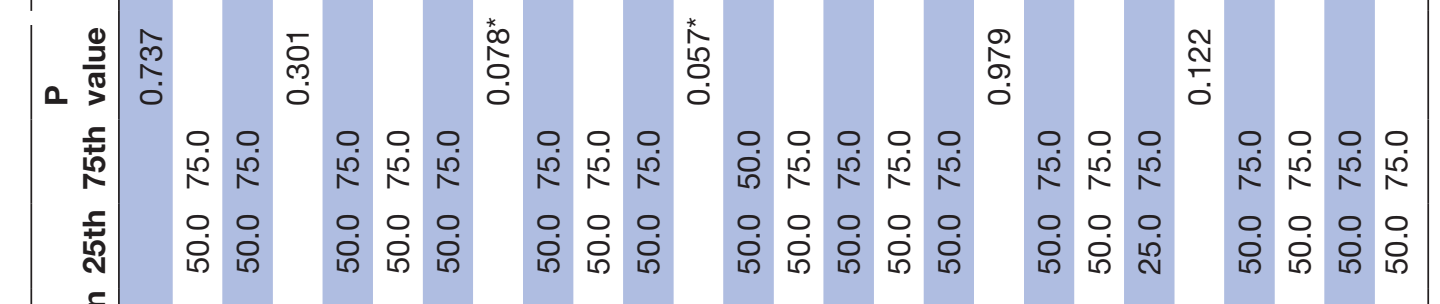

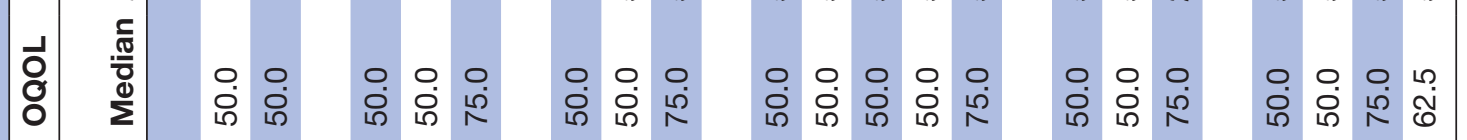

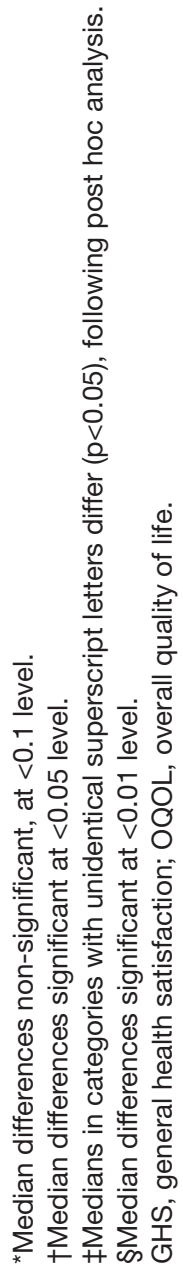
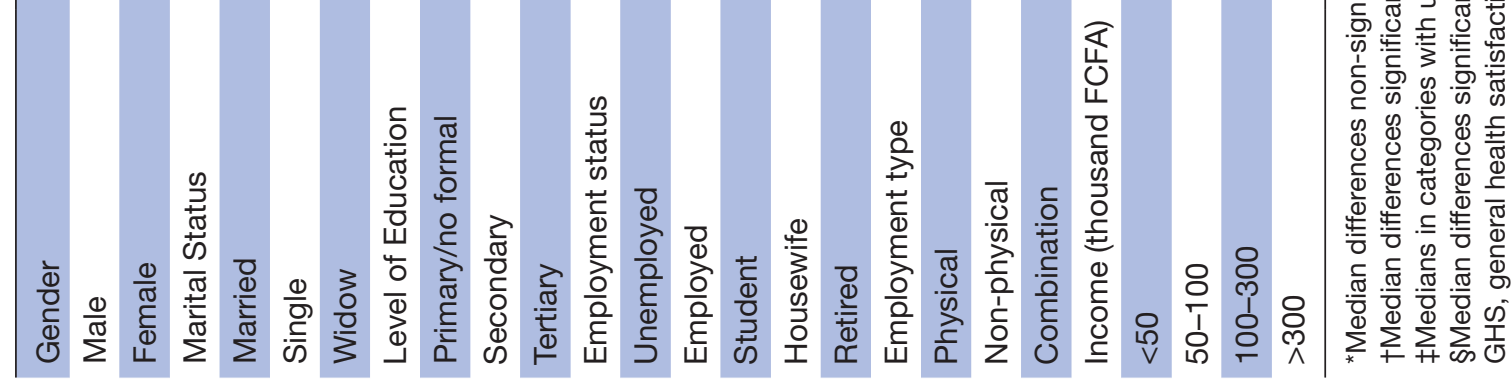

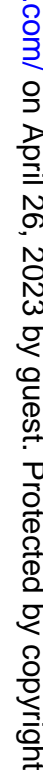


Table 5 Multivariate regression model showing the influence of various domains on OQOL and GHS scores

\begin{tabular}{|c|c|c|c|c|}
\hline & \multicolumn{2}{|c|}{$\mathrm{OQOLaR}^{2}=0.350$} & \multicolumn{2}{|c|}{$\mathrm{GHSaR}^{2}=0.151$} \\
\hline & $\beta$ & $95 \% \mathrm{Cl}$ & $\beta$ & $95 \% \mathrm{Cl}$ \\
\hline Physical health domain & -0.25 & -0.54 to 0.03 & 0.42 & -0.15 to 0.99 \\
\hline Psychological domain & 0.10 & -0.10 to 0.30 & 0.36 & -0.03 to 0.74 \\
\hline Social relationships domain & $0.26^{*}$ & 0.11 to 0.41 & 0.14 & -0.17 to 0.44 \\
\hline Environmental domain & $0.43 \dagger$ & 0.22 to 0.64 & -0.09 & -0.51 to 0.34 \\
\hline
\end{tabular}

OQOL model adjusted for age, gender, educational level and employment status.

GH model adjusted for age, gender and type of employment.

${ }^{*}$ Beta coefficient significant at $<0.01$ level.

†Beta coefficient significant at $<0.001$ level

$\ddagger$ Beta coefficient significant at $<0.05$ level.

$\beta$, beta coefficient; $\mathrm{GH}$, general health; OQOL, overall quality of life.

The highest scored (least impaired) domains of HRQoL in our study were the PSD, followed by the SRD. This order was rather uncommon in other literature. In most other LBP patient groups (Iran, Taiwan, Austria, Brazil, Poland and Bosnia), ${ }^{18-20} 2738394142$ the SRD was the highest, with the PSD usually falling much lower in the third place. The PSD scores were reported to be most impaired (lowest) in two studies in Taiwan and Poland. ${ }^{19}{ }^{41}$ We found this difference in perceived psychological well-being between our patients and those in other settings rather peculiar. We speculate that it may be related to sociocultural particularities in our setting that could be further investigated.

There was no difference in HRQoL domain scores between males and female CLBP patients in our study, and in some others. ${ }^{1827}$ One study, however, reported better PSD scores in males with CLBP compared with females. ${ }^{42}$ In a like manner, age did not affect any of the HRQoL domains in our patients, but findings in previous literature have thus far been variable. For example, in a cohort of CLBP patients in Brazil, older age was associated with poorer scores in all four domains. ${ }^{27}$ In Bosnia, older patients had poorer PSD and PHD scores. ${ }^{42}$ However, our findings are mirrored in a Polish study with similar mean age. ${ }^{39}$

In some other studies, pain intensity significantly influenced certain HRQoL domains. ${ }^{19}{ }^{39}$ However, for ours, it had no significant influence on any HRQoL score after controlling for confounders. On the other hand, disability is also described in the literature as a key predictor of lower QoL in CLBP. ${ }^{19} 2741$ Disability in our patients was strongly associated with the PSD score, but less so with the END, and not at all with the PHD after adjusting for confounders, which is at variance with other reports. ${ }^{9241}$ In addition, this study found no relation between disability and perception of OQOL, which is contrary to findings in Taiwanese and Polish cohorts. ${ }^{19} 41$

After controlling for age, sex and other sociodemographic and clinical variables, being a current smoker and having documented radiologic lesions were the only factors independently associated with worse physical health scores. Smoking has been previously explored in Brazilian CLBP patients, but was found to have no influence on the PHD. ${ }^{27}$ On examination of predictors of PSD, in addition to a strong relationship between disability and psychological QoL, persons with a longer duration of their back pain episode also had poorer PSD QoL. Duration, however, did not influence any other HRQoL score. In a Polish cohort, duration of LBP rather influenced the END score. ${ }^{39}$

In our study, tertiary education predicted better environmental QoL while higher income predicted better social QoL. Education equally seemed to play a role in perceived OQOL. Students and persons with universitylevel education had higher scores. Our results did not conform to previous reports ${ }^{27} 39$ in which educational level and income did not significantly influence any of the HRQoL scores after controlling for confounders. This could reflect the better socioeconomic status of the populations in these countries. Examining employment in more detail revealed that work type seems to influence health satisfaction in our CLBP patients and logically so. Subjects whose occupations involved physical exertion had significantly lower health satisfaction.

Environmental and social domains predicted patients' perception of their OQOL. A previous study rather discovered a relationship between OQOL and the physical and PSD domains. ${ }^{19}$ These findings illustrate how factors unique to each population setting could influence HRQoL in identical disease states.

This study had certain limitations. Using a cross-sectional study design limited our ability to determine causality, as would have been possible with a prospective cohort design. In addition, our study was prone to selection bias owing to the use of a non-random sampling technique and the selected nature (hospital based) of the study. Our findings cannot be generalised without caution as they likely reflect the situation at the study facility. Furthermore, we did not explicitly assess the aetiology of associated symptoms. We acknowledge that they may have been due to other health problems and not necessarily LBP. Finally, there is no culturally adapted, validated, generic HRQoL questionnaire specific for Cameroon. Furthermore, there are no population norms for WHOQOLBREF in Cameroon. This lack of a reference limits our possibility to carefully analyse health outcomes. 
However, we sought to reduce some of the bias by choosing a widely validated tool specially developed to be applied across cultures and permit comparisons across various settings. Future research to develop a culturally adapted generic HRQoL tool for our setting and establish population norms of existing tools could go a long way in improving the evaluation of the impact of CLBP on HRQoL.

\section{CONCLUSIONS}

Our results suggest that CLBP impedes the HRQoL of affected patients. The factors that influence HRQoL in CLBP patients vary across its various component domains. Multicomponent management strategies, especially those that reduce disability and mitigate environmental and socioeconomic barriers to healthcare should be considered to improve the HRQoL in patients with CLBP. To the best of our knowledge, this study is the first of its kind in Cameroon to provide evidence on the HRQoL of patients with chronic LBP, as well as the determinants of QoL in this population. Our findings are thus relevant for health policy-makers, as it has unearthed significant determinants that could be targeted in order to allay the burden of CLBP.

\section{Author affiliations}

${ }^{1}$ Cameroon Baptist Convention Health Service, Bamenda, Cameroon

${ }^{2}$ Faculty of Health Sciences, University of Buea, Buea, Cameroon

${ }^{3}$ School of Allied Health Sciences, Griffith University, Gold Coast, QLD, Australia

${ }^{4}$ School of Medicine, Griffith University, Gold Coast, QLD, Australia

${ }^{5}$ Non-communicable diseases Unit, Clinical Research Education, Networking \&

Consultancy (CRENC), Douala, Cameroon

${ }^{6}$ Rheumatology Unit, Douala General Hospital, Douala, Cameroon

${ }^{7}$ Department of Internal Medicine \& Specialties, Faculty of Medicine \& Biomedical

Sciences, University of Yaounde I, Yaounde, Cameroon

${ }^{8}$ Faculty of Social \& Management Sciences, University of Buea, Buea, Cameroon

\section{Twitter Leopold Ndemnge Aminde @|_aminde}

Acknowledgements We are sincerely grateful to the staff at the Rheumatology Unit of the Douala General Hospital for their cooperation during this study. We are equally thankful to all our patients who assisted in designing the questionnaire and those who accepted to take part in the study.

Contributors Study conception and design: JAA, LNA and MDB. Data collection: JAA, MDB, FKL, FMK. Statistical analysis: JAA and LNA. Drafting of manuscript: JAA and LNA. Critical review of manuscript: LNA, MDB, JAA, AMC and EVY.

Funding The authors have not declared a specific grant for this research from any funding agency in the public, commercial or not-for-profit sectors.

Competing interests None declared.

Patient and public involvement Patients and/or the public were involved in the design, or conduct, or reporting, or dissemination plans of this research. Refer to the Methods section for further details.

Patient consent for publication Not required.

Ethics approval Ethical approval to carry out the study was obtained from the University of Buea, Faculty of Health Sciences Institutional Review Board, with approval number: 2017/003/UB/SG/RB/FHS.

Provenance and peer review Not commissioned; externally peer reviewed.

Data availability statement Data are available on reasonable request. Deidentified participant data are available on reasonable request from the corresponding author:jeannineatemanyingu@rocketmail.com 0000-0003-31496494 (ORCID identifier).
Open access This is an open access article distributed in accordance with the Creative Commons Attribution Non Commercial (CC BY-NC 4.0) license, which permits others to distribute, remix, adapt, build upon this work non-commercially, and license their derivative works on different terms, provided the original work is properly cited, appropriate credit is given, any changes made indicated, and the use is non-commercial. See: http://creativecommons.org/licenses/by-nc/4.0/.

\section{ORCID iDs}

Jeannine Anyingu Aminde http://orcid.org/0000-0003-3149-6494

Leopold Ndemnge Aminde http://orcid.org/0000-0003-2787-7518

\section{REFERENCES}

1 Hoy D, Bain C, Williams G, et al. A systematic review of the global prevalence of low back pain. Arthritis \& Rheumatism 2012;64:2028-37.

2 Hoy D, Brooks P, Blyth F, et al. The epidemiology of low back pain. Best Pract Res Clin Rheumatol 2010;24:769-81.

3 James SL, Abate D, Abate $\mathrm{KH}$, et al. Global, regional, and national incidence, prevalence, and years lived with disability for 354 diseases and injuries for 195 countries and territories, 1990-2017: a systematic analysis for the global burden of disease study 2017 . The Lancet 2018;392:1789-858.

4 Louw QA, Morris LD, Grimmer-Somers K. The prevalence of low back pain in Africa: a systematic review. BMC Musculoskelet Disord 2007;8:105.

5 United Nations, Department of Economic and Social Affairs, Population Division. World population prospects 2019, 2019. Available: https://population.un.org/wpp/DataQuery/

6 Lekpa FK, Doualla MS, Singwe-Ngandeu M, et al. AB0847 nonspecific chronic low back pain is common in sub-Saharan Africa: a hospital-based study in Cameroon. Ann Rheum Dis 2016;75:1192.

7 Singwe-Ngandeu M, Meli J, Ntsiba H, et al. Rheumatic diseases in patients attending a clinic at a referral hospital in Yaounde, Cameroon. East Afr Med J 2007;84:404-9.

8 Doualla M, Aminde J, Aminde LN, et al. Factors influencing disability in patients with chronic low back pain attending a tertiary hospital in sub-Saharan Africa. BMC Musculoskelet Disord 2019;20:25.

9 Chou R. Low back pain (chronic). BMJ Clin Evid 2010;10:1116.

10 Burton AK, Balagué F, Cardon G, et al. Chapter 2. European guidelines for prevention in low back pain : November 2004. Eur Spine J 2006;15:s136-68.

11 Niv D, Kreitler S. Pain and quality of life. Pain Pract 2001;1:150-61.

12 Centers for Disease Control and Prevention. Health-Related quality of life (HRQOL), 2018. Available: https://www.cdc.gov/hrqol/concept. htm [Accessed 18 Jul 2019].

13 Group W. Study protocol for the world Health organization project to develop a quality of life assessment instrument (WHOQOL). Qual Life Res 1993;2:153-9.

14 Carr AJ, Gibson B, Robinson PG. Measuring quality of life: is quality of life determined by expectations or experience? BMJ 2001;322:1240-3.

15 Németh G. Health related quality of life outcome instruments. Eur Spine J 2006;15:S44-51.

16 Hand C. Measuring health-related quality of life in adults with chronic conditions in primary care settings. Can Fam Physician 2016;62:e375-83.

17 Centers for Disease Control and Prevention. Measuring healthy days. Atlanta, Georgia, November, 2000.

18 Darzi MT, Pourhadi S, Hosseinzadeh S, et al. Comparison of quality of life in low back pain patients and healthy subjects by using WHOQOL-BREF. J Back Musculoskelet Rehabil 2014;27:507-12.

19 Horng Y-S, Hwang Y-H, Wu H-C, et al. Predicting health-related quality of life in patients with low back pain. Spine 2005;30:551-5.

20 Pieber K, Stein KV, Herceg M, et al. Determinants of satisfaction with individual health in male and female patients with chronic low back pain. J Rehabil Med 2012;44:658-63.

21 Altuğ F, Ünal A, Kilavuz G, et al. Investigation of the relationship between kinesiophobia, physical activity level and quality of life in patients with chronic low back pain1. J Back Musculoskelet Rehabil 2016;29:527-31.

22 Marty M, Rozenberg S, Duplan B, et al. Quality of sleep in patients with chronic low back pain: a case-control study. Eur Spine $J$ 2008;17:839-44.

23 Antunes RS, de Macedo BG, Amaral TdaS, et al. Pain, kinesiophobia and quality of life in chronic low back pain and depression. Acta Ortop Bras 2013;21:27-9. 
24 Orenius T, Koskela T, Koho P, et al. Anxiety and depression are independent predictors of quality of life of patients with chronic musculoskeletal pain. J Health Psychol 2013;18:167-75.

25 Schaller A, Dejonghe L, Haastert B, et al. Physical activity and health-related quality of life in chronic low back pain patients: a cross-sectional study. BMC Musculoskelet Disord 2015;16:62.

26 Sezgin M, Hasanefendioğlu EZ, Sungur MA, et al. Sleep quality in patients with chronic low back pain: a cross-sectional study assesing its relations with pain, functional status and quality of life. $J$ Back Musculoskelet Rehabil 2015;28:433-41.

27 Stefane T, dos SAM, Marinovic A, et al. Chronic low back pain: pain intensity, disability and quality of life. Acta Paul Enferm 2013;26:14-20.

28 Ogunlana MO, Odunaiya NA, Dairo MD, et al. Predictors of healthrelated quality of life in patients with non-specific low back pain. Af Jrl. Phys Rehab Sci 2012;4:15-22.

29 Kovacs FM, Abraira V, Zamora J, et al. Correlation between pain, disability, and quality of life in patients with common low back pain Spine 2004;29:206-10.

30 Institut National de la Statistique. Chapitre 4: Caractéristiques de la population, Annuaire Statistique Du Cameroun, 2015. Available: http://www.statistics-cameroon.org/news.php?id=345 2016-5 [Accessed 18 Jul 2019].

31 Deyo RA, Dworkin SF, Amtmann D, et al. Report of the NIH Task force on research standards for chronic low back pain. Phys Ther 2015;95:e1-18.

32 de Vet HCW, Heymans MW, Dunn KM, et al. Episodes of low back pain: a proposal for uniform definitions to be used in research. Spine 2002;27:2409-16.

33 Lauridsen $\mathrm{HH}$, Hartvigsen J, Manniche C, et al. Responsiveness and minimal clinically important difference for pain and disability instruments in low back pain patients. BMC Musculoskelet Disord 2006;7:82.

34 Skevington SM, McCrate FM. Expecting a good quality of life in health: assessing people with diverse diseases and conditions using the WHOQOL-BREF. Health Expect 2012;15:49-62.

35 World Health Organization, Division of Mental Health. WHOQOLBREF: introduction, administration, scoring and generic version of the assesment : field trial version, 1996. Available: https://apps.who. int/iris/handle/10665/63529 [Accessed 18 Jul 2019].

36 Feder K, Michaud DS, Keith SE, et al. An assessment of quality of life using the WHOQOL-BREF among participants living in the vicinity of wind turbines. Environ Res 2015;142:227-38.

37 World Medical Association (WMA). Declaration of Helsinki - Version 2013, 2019. Available: https://www.wma.net/what-we-do/medicalethics/declaration-of-helsinki/ [Accessed 18 Jul 2019].

38 Roizenblatt S, Souza AL, Palombini L, et al. Musculoskeletal pain as a marker of health quality. findings from the epidemiological sleep study among the adult population of São Paulo City. PLoS One 2015;10:e0142726.

39 Uchmanowicz I, Kołtuniuk A, Stępień A, et al. The influence of sleep disorders on the quality of life in patients with chronic low back pain. Scand J Caring Sci 2019;33:119-27.

40 United Nations Statistics Division. National accounts estimates of main aggregates 2019, 2019. Available: https://data.un.org/

41 Talaga S, Magiera Z, Kowalczyk B, et al. Problems of patients with degenerative disease of the spine and their guality of life. Ortop Traumatol Rehabil 2014;16:617-27.

42 Macak Hadziomerovic A, Vilic M, Ajnadzic N, et al. The effects of age and gender on the quality of life of people with chronic back pain in Bosnia and Herzegovina. DCID 2017;28:129-38. 